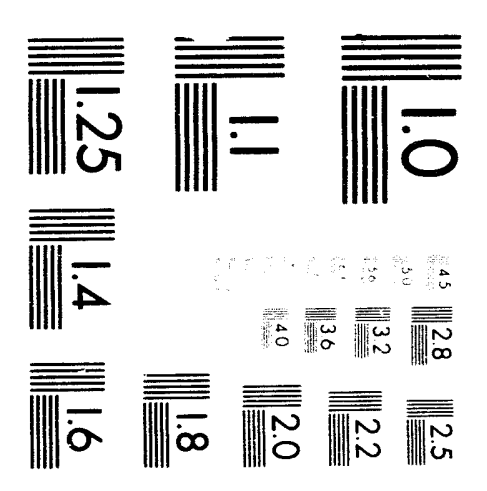



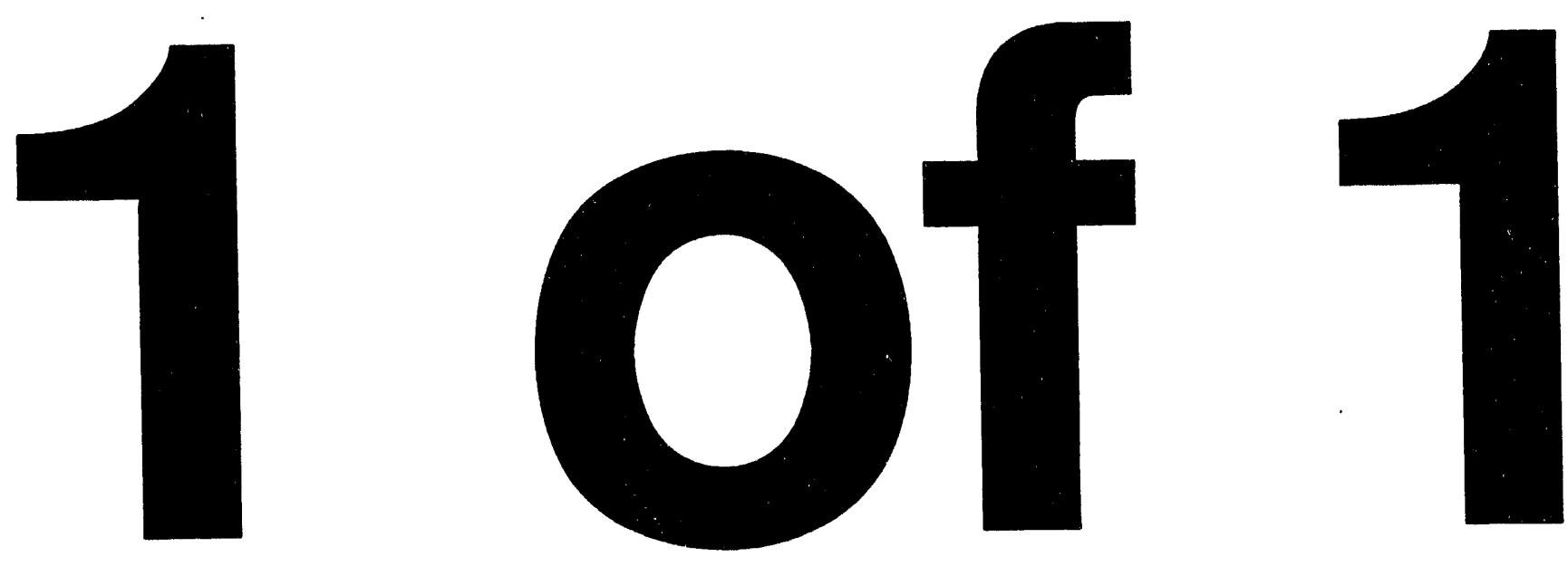


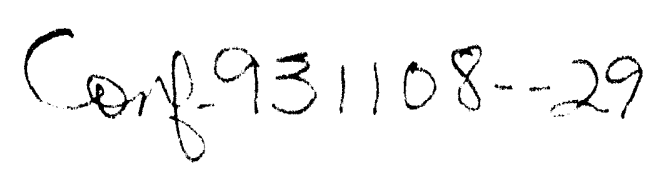

\section{Invited Paper}

Fall Meeting of the Materials Research Society

Boston, Massachusetts

November 29-December 3, 1993

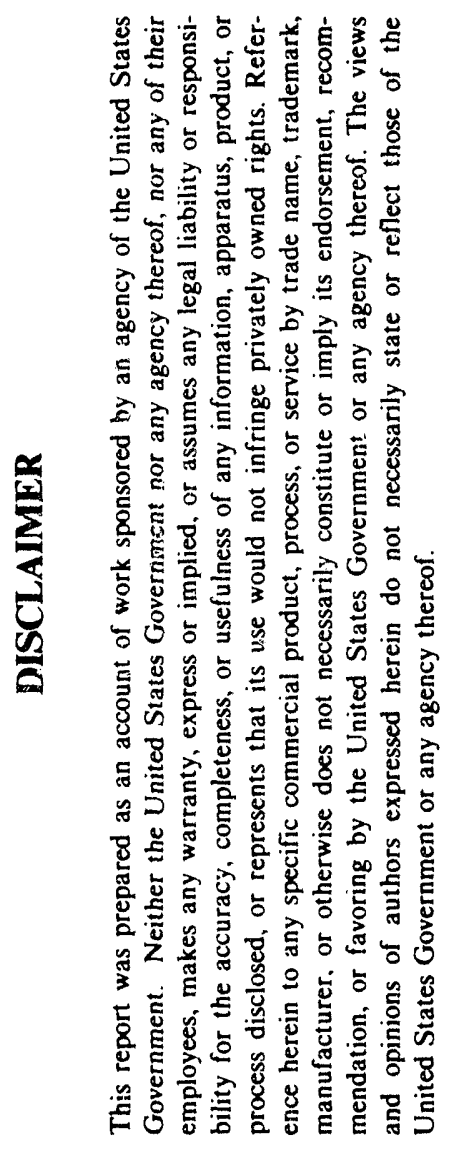

\section{Structural Analysis of Amorphous Phosphates Using High Performance Liquid Chromatography ${ }^{*}$}

B. C. Sales, L. A. Boatner, B. C. Chakoumakos

J. C. McCallum, J. O. Ramey, and R. A. Zuhr

"The submitted manuscript has bren authored by a contractor of the U.S. Government under contract No. DE-AC05-84OR21400. Accordingly, the U.S. Government retains a nonexclusive, royaltyfree license to publish or reproduce the published form of this contribution, or allow others to do so, for U.S. Government purposes."

* Research sponsored by the Division of Materials Sciences, U.S. Department of Energy under contract no. DE-AC05-84OR21400 with Martin Marietta Energy Systems, Inc.

$$
\text { int }
$$




\title{
STRUCTURAL ANALYSIS OF AMORPHOUS PHOSPHATES USING HIGH PERFORMANCE LIQUID CHROMATOGRAPHY
}

\author{
B. C. SALES, L. A. BOATNER, B. C. CHAKOUMAKOS, J. C. MđC' '.LUM, J. O \\ RAMEY, AND R. A. ZUHR \\ Solid State Division, Oak Ridge National Laboratory; Oak Ridge, TN, 37830-6056
}

\section{ABSTRACT}

The technique of high-performance liquid chromatography (HPLC) provides unique detailed information regarding the structure of partially disordered or amorphous phosphate solids. Applications of the experimental technique of HPLC to phosphate solids are reviewed, and examples of the type of information that can-beobtained with HPLC are presented.

\section{INTRODUCTION}

Determining the atomic-scale structure of amorphous solids has proven to be a formidable scientific and technological problem for the past 100 years. While significant advances have been made in understanding the structure-property relationships in crystalline solids, similar progress has not been achieved in the case of amorphous materials. For amorphous solids, the standard analytical techniques are primarily sensitive to short range order- normally defined as spatial correlations between an atom and neighboring atoms separated by no more than 5 or $10 \AA$. These techniques include: $X$-ray or neutron diffraction, nuclear magnetic resonance, extended $X$-ray absorption fine structure measurements, electron paramagnetic resonance, Mossbauer spectroscopy, Raman spectroscopy, infrared spectroscopy, and optical spectroscopy. The technique of high-performance liquid chromatography (HPLC) is, to our knowledge, the only technique currently capable of measuring the distribution of specific structural units in the amorphous state that are between 10 and $100 \AA$ in size. The major disadvantage of the HPLC technique is that, at present, it can only be reliably applied to analyzing the structures of phosphates.

Inorganic phosphates encompass a large class of important materials whose applications include: catalysts, ion-exchange media, solid electrolytes for batteries, linear and nonlinear optical components, chelating agents, synthetic replacements for bone and teeth, phosphors, detergents, and fertilizers [1,2]. Phosphates may, in fact, represent the most interesting class of new inorganic materials because of the adaptability of the $\mathrm{PO}_{4}$ tetrahedra in bonding to other diverse structural units. Phosphate ions also represent a unique link between living systems and the inorganic world [3]. For this reason, phosphate minerals play an important role in tracing the earliest life forms and in the reconstruction of biomolecular evolution.

\footnotetext{
"Research sponsored by the Division of Materials Sciences, U. S. Department of Energy under Contract No. DE-AC05-84OR21400 with Martin Marietta Energy Systems, Inc.
} 


\section{HPLC AND PHOSPHATES: EXPERIMENTAL TECHNIQUE}

The metal-phosphates of interest here consist of chains of corner-linked $\mathrm{PO}_{4}$ tetrahedra (Fig 1); which are, in turn, bonded to each other by the metal cations. A crystalline phosphate of this type will generally have a phosphate chain of only one specific length in its structure while an amorphous phosphate solid will be characterized by a distribution of "spaghetti-like" chains of different lengths. By applying the HPLC technique, the relative concentration and distribution of phosphate chains in an amorphous solid can be determined quantitatively. Selected crystalline-phosphate standards are used to calibrate the HPLC system so that a particular peak in the HPLC chromatogram can be unambiguously assigned to a known phosphate anion.
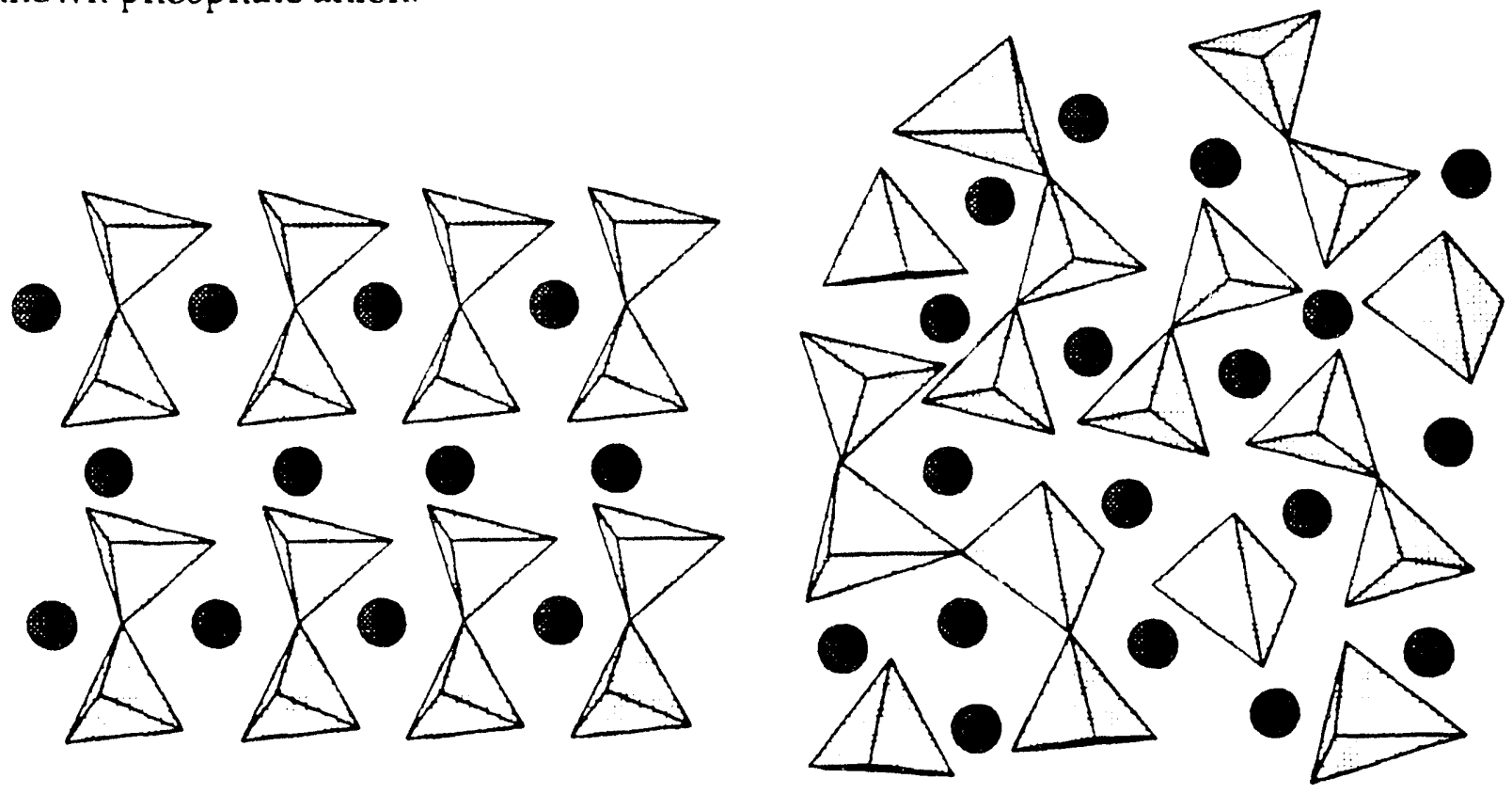

FIG. 1 Schematic drawing of (left) a crystalline metal-phosphate compound with only $\mathrm{P}_{2}$ chains (two cnrner-linked $\mathrm{PO}_{4}$ tetrahedra) and (right) an amorphous metalphosphate with the same overall composition. In the amorphous phosphate, both longer and shorter phosphate chains are present. The metal cations are represented by the shaded spheres.

The HPLC technique is applicable to most metal-phosphate solids because of the manner in which these solids dissolve in high-pH aqueous solutions. In the present experiments the phosphate solid is placed in a pH 10 solution of $0.22 \mathrm{M} \mathrm{NaCl}$ and $5 \times 10^{-3} \mathrm{M}$ Na4EDTA. Diffusion of water into the solid leads to hydration, disentanglement, and subsequent transport of entire polyphosphate anion chains into solution. Acid/base reactions between the $\mathrm{H}^{+}$and $\mathrm{OH}^{-}$ions and the $\mathrm{P}-\mathrm{O}$-Metal groups affect the ionic interaction between the chains and assist in the disentanglement and transport of the chains into solution [4-7]. The presence of the EDTA in the solution is apparently critical when dealing with high-field-strength cations such as $\mathrm{Mg}^{+2}$ or $\mathrm{Fe}^{+3}$. Once the "spaghetti-like" chains are in the chromatography solution, they are quite stable and do not exhibit any tendency toward either hydrolysis or 
polymerization for a period of at least $24 \mathrm{~h}$ [8]. The solution containing the dissolved phosphate solid is passed through a 0.45 micron filter and then injected into the HPLC system where the chains of linked $\mathrm{PO}_{4}$ tetrahedra are bound on an ion-exchange column. An HPLC chromatogram is obtained as the sodium chloride molarity at the ion-exchange column is programmed to increase as a function of time, and thereby, sequentially release phosphate chains of various lengths beginning with phosphate anions consisting of only one $\mathrm{PO}_{4}$ tetrahedron $\left(\mathrm{P}_{1}\right)$, then two $\mathrm{PO}_{4}$ tetrahedra $\left(\mathrm{P}_{2}\right)$, three $\mathrm{PO}_{4}$ tetrahedra $\left(\mathrm{P}_{3}\right)$ and so forth. The HPLC chromatogram, therefore, consists of a series of peaks whose position in time (i.e., the time at which the sodium chloride molarity has reached the value at which specific phosphate anions are released from the column) corresponds to the presence of $\mathrm{PO}_{4}$ chains of a given length and where the area under these peaks is proportional to the amount of phosphorus contained in chains of that length. A detailed discussion of the HPLC system used in the present experiments has been given previousiy $[9,10]$.

The strongest evidence that the information obtained from an HPLC chromatogram represents the phosphate anion distribution in the amorphous solid comes from the application of the same technique to crystalline solids. In a crystalline phosphate compound, the type of phosphate anion present in the solid can be determined independently using either X-ray or neutron diffraction, and this information can then be compared to the result obtained from an HPLC experiment on the same crystalline solid. For a large number of crystalline phosphate compounds, HPLC and diffraction results are in perfect agreement. In calibrating our HPLC system, a "standard solution" is used that is prepared by dissolving measured amounts of several crystalline phosphate compounds in the chromatography solution. The chromatogram obtained from this solution consists of a series of peaks (Fig 2), with each crystalline compound contributing only one peak whose area is proportional to the amount of that phosphate solid in solution.

FIG. 2. HPLC chromatogram of a tandard solution" prepared by dissolving several crystalline-phosphate compounds in the chromatography solution. Each of the phosphate compounds listed in the upper right of the figure contributes only one phosphate anion and is responsible for only one of the peaks in the chromatogram. The subscript $m$, for two of the compounds, indicates that these two solids contain cyclic (i.e. ringlike) phosphate anions (trimetaphosphate and tetrametaphosphate).

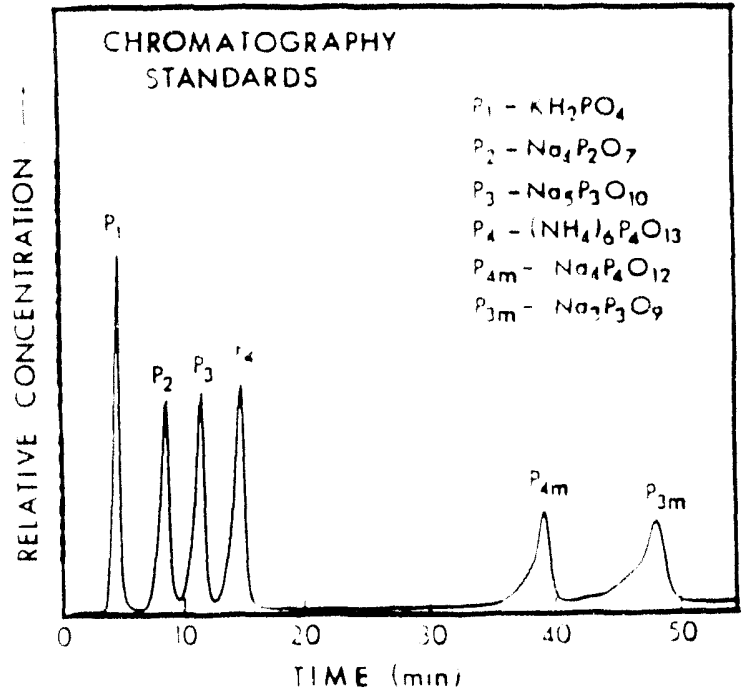


HPLC AND PHOSPHATES: EXAMPLES

\section{Dehydration of $\mathrm{MgHPO}_{4} \cdot 3 \underline{\mathrm{H}}_{2} \mathrm{O}$}

Synthetic crystals of the mineral newberyite $\left(\mathrm{MgHPO}_{4} \bullet 3 \mathrm{H}_{2} \mathrm{O}\right)$ were grown from aqueous solution. Our interest in this material was stimulated by the previous work of Kanazawa and co-workers (11) who noted that as the waters of hydration were removed from newberyite during heating, the material underwent a crystalline-toamorphous transition. Crystalline newberyite that is heated above about $150^{\circ} \mathrm{C}$ becomes amorphous and remains amorphous even when heated to temperatures as high as $600{ }^{\circ} \mathrm{C}$. Above $600{ }^{\circ} \mathrm{C}$, however, crystalline $\mathrm{Mg}_{2} \mathrm{P}_{2} \mathrm{O}_{7}$ finally forms. This type of crystalline-to-amorphous transition upon heating is unusual and only occurs for a few materials.

The powder X-ray diffraction (XRD) results for $\mathrm{MgHPO}_{4} \bullet 3 \mathrm{H}_{2} \mathrm{O}$ crystals heated for $1 \mathrm{~h}$ in flowing oxygen at the indicated temperatures are shown in Fig. $3[12,13]$. Specimens annealed at temperatures between room temperature and about $100{ }^{\circ} \mathrm{C}$ exhibited the characteristic diffraction pattern of crystalline newbervite as shown in the top trace of Fig 3. For crystals heated between $150^{\circ} \mathrm{C}$ and $600{ }^{\circ} \mathrm{C}$, however, no evidence of crystallinity could be detected by $X$-ray analysis, and as shown in Fig. 3 , the $X$-ray patterns in this temperature region were all rather similar with only weak scattering evident at low scattering angles. Between $150^{\circ} \mathrm{C}$ and $600^{\circ} \mathrm{C}$, the material is, therefore, amorphous by the standard definition of this state of matter.

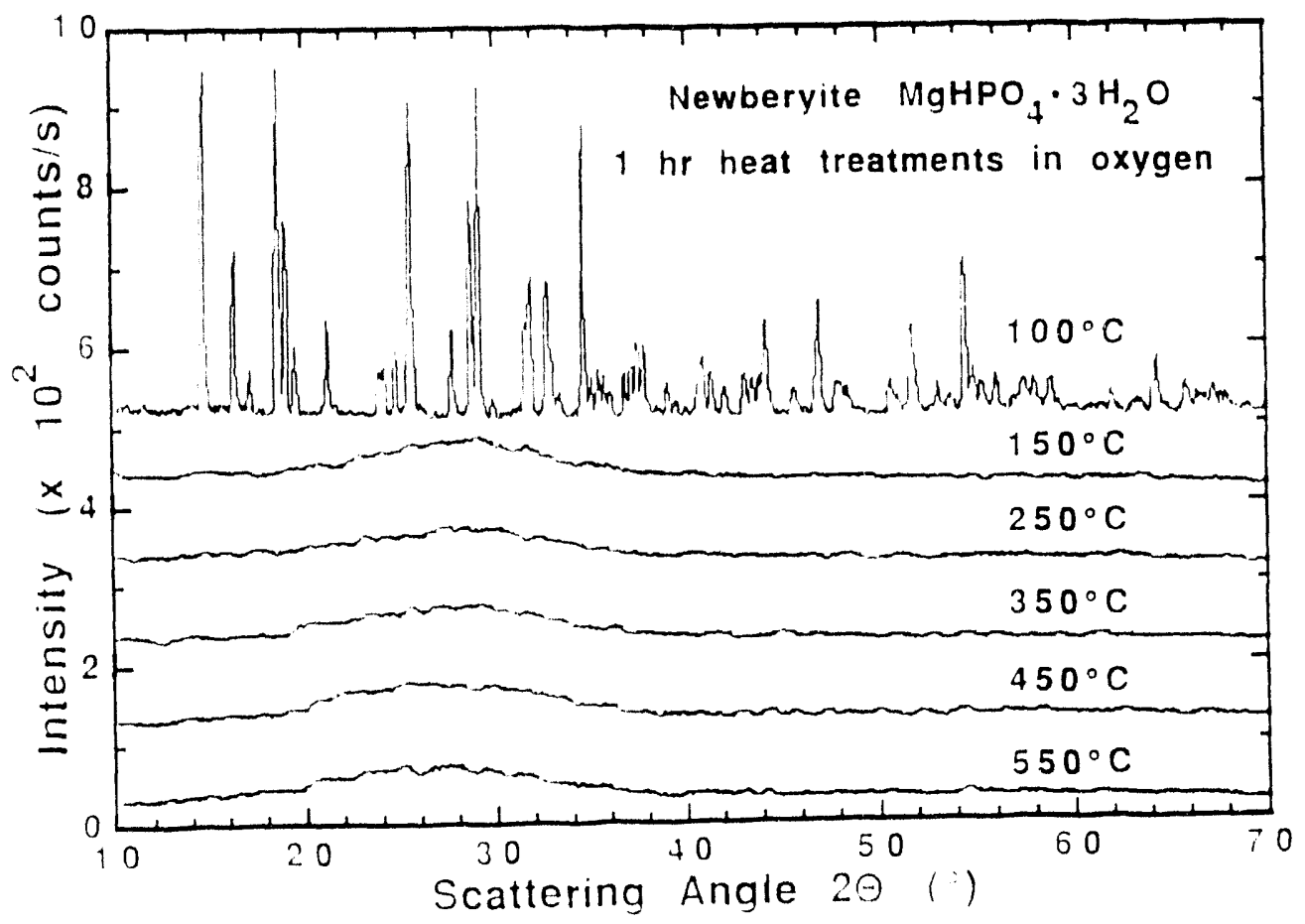

FIG. 3. Powder X-ray diffraction patterns $\left(\mathrm{Cu} \mathrm{K} \alpha\right.$ radiation) from $\mathrm{MgHPO}_{4} \bullet 3 \mathrm{H}_{2} \mathrm{O}$ samples heated in flowing oxvgen for $1 \mathrm{~h}$ at the indicated temperatures. For temperatures above $150^{\circ} \mathrm{C}$, the $\mathrm{XRD}$ results show that the material is amorphous. 
The HPLC method was used to determine the distribution of chain lengths (phosphate anions) for the amorphous phosphates formed by heating newbervite over the same temperature range as that used to obtain the XRD results. The corresponding HPLC data for this set of samples are shown in Fig 4. The significant changes in the phosphate-anion distribution that occur when heating newberyite between 100 and $550^{\circ} \mathrm{C}$ are immediately apparent in Fig 4 . For a crystalline sample of $\mathrm{MgHPO}_{4} \bullet 3 \mathrm{H}_{2} \mathrm{O}$ heated to $100^{\circ} \mathrm{C}$, the chromatogram consists of a single $P_{1}$ (i.e. orthophosphate anion) peak in agreement with the known structure of newberyite $[14,15]$. During the initial stages of the dehydration process $\left(100-300^{\circ} \mathrm{C}\right)$, the percentage of $\mathrm{P}_{2}$ chains increases as one would expect for the transition from an orthophosphate to a pyrophosphate (Fig. 5). Between 300 and $500{ }^{\circ} \mathrm{C}$, however, there is a surprising decrease in the $\mathrm{P}_{2}$ concentration which may reflect the thermodynamic tendency of the material to form $\mathrm{MgHPO}_{4}$, a phase that exists as a crystalline solid for all of the other alkaline earths, but has not been observed for $\mathrm{Mg}$.

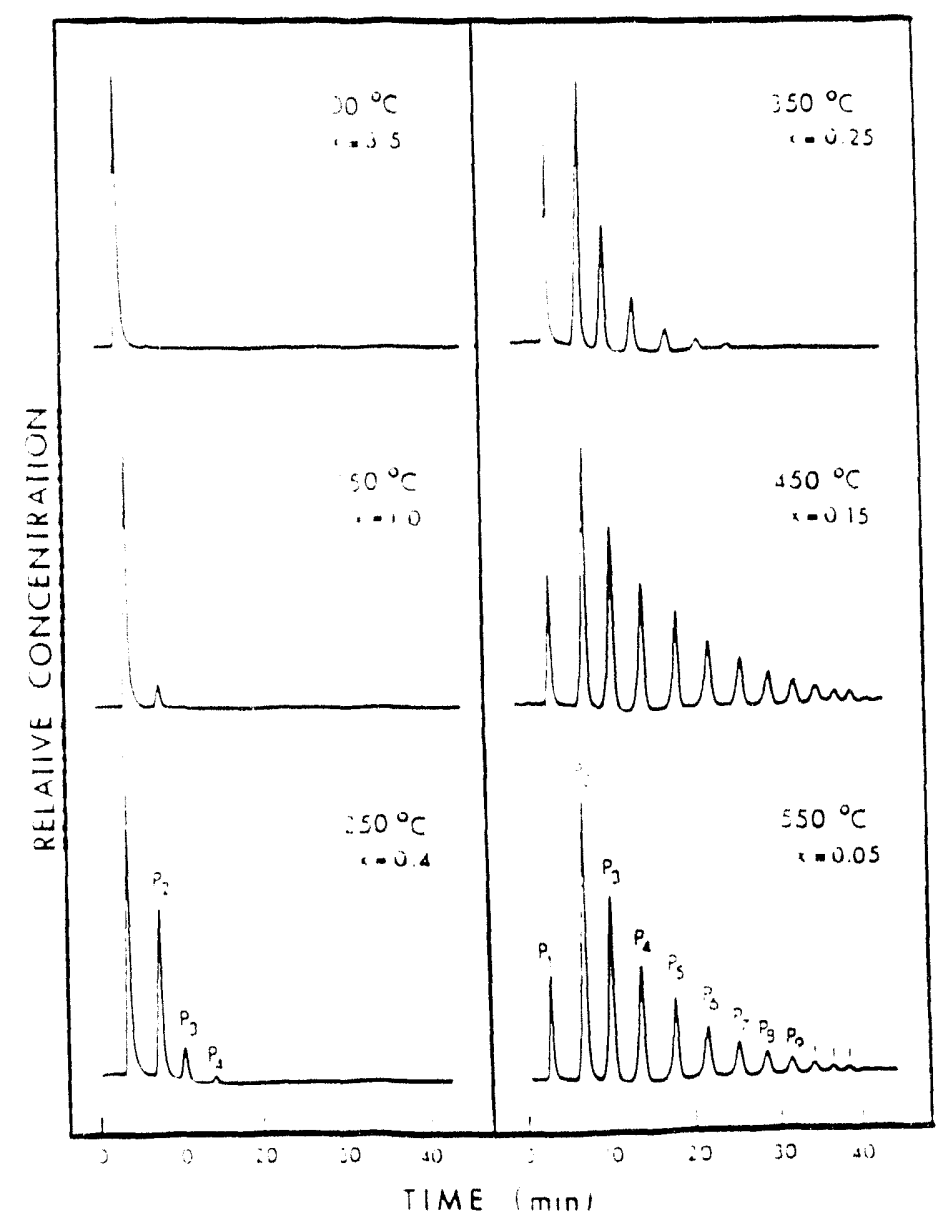

FIG. 4. HPLC chromatograms from $\mathrm{MgHPO}_{4} \bullet 3 \mathrm{H}_{2} \mathrm{O}$ samples heated in flowing oxygen for $1 \mathrm{~h}$ at the indicated temperatures. The position in time (or $\mathrm{NaCl}$ molarity) and the area under each peak in the chromatogram indicate respectively the identity and quantity of a particular phosphate anion. A phosphate anion labeled $P_{n}$ means that the anion consists of $n$ corner-linked $\mathrm{PO}_{4}$ tetrahedra. The "water content" $x$ of each sample, as determined by thermogravimetric analysis, is also shown in the figure. 
FIG. 5. Results from an analysis of the chromatograms for $\mathrm{MgHPO}_{4} \bullet 3 \mathrm{H}_{2} \mathrm{O}$ samples annealed in flowing oxygen at temperatures between room temperature and $600^{\circ} \mathrm{C}$. (a) Percentage of phosphorus present in the $P_{3}$ and $P_{2}$ anions as a function of annealing temperature. (b) Percentage of phosphorus present in the $\mathrm{P}_{5}, \mathrm{P}_{7}$, and $\mathrm{Pa}$ anions. (c) Average phosphate chain length at each annealing temperature.

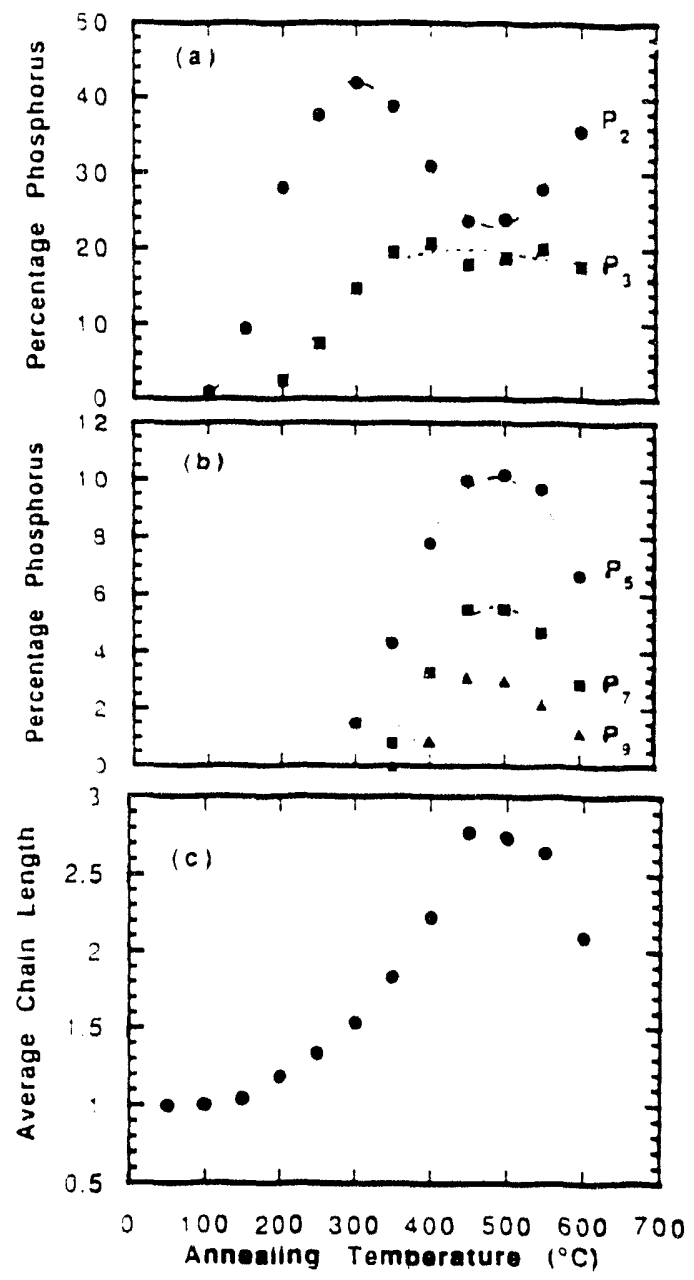

Samples heated at $500^{\circ} \mathrm{C}$ exhibit the highest concentrations of longer chains (i.e. $P_{5}$ to $P_{13}$ ) and the maximum observed average phosphate chain length of about 2.75 (Fig. 5). At $500{ }^{\circ} \mathrm{C}$, almost all of the water and hydrogen have been removed from the newberyite (as determined by thermogravimetric analysis). If a formal charge balance between the $\mathrm{Mg}$ cations and phosphate anions were maintained, the average chain length should be 2.0. Samples heated to temperatures near $500^{\circ} \mathrm{C}$ would, therefore, be expected to have substantial internal stresses due to charge imbalance effects and accordingly, the amorphous phases may exhibit unusual dielectric and mechanical properties. The average chain length and concentration of the longer phosphate chains (i.e., $>\mathrm{P}_{5}$ ) begin to decrease for samples annealed at temperatures $>500{ }^{\circ} \mathrm{C}$. These structural changes are precursors to the formation of crystalline magnesium pyrophosphate $\left(\mathrm{Mg}_{2} \mathrm{P}_{2} \mathrm{O}_{7}\right)$ that is only observed by $\mathrm{XRD}$ at temperatures above 600 ${ }^{\circ} \mathrm{C}$. Similar local structural changes have been reported for other systems near the onset of devitrification [16]. 


\section{Crystallization of $\mathrm{Pb}_{2} \mathrm{P}_{2} \mathrm{O}_{7}$ Glass}

Lead pyrophosphate was synthesized by melting and reacting appropriate amounts of $\mathrm{PbO}$ and $\mathrm{NH}_{4} \mathrm{H}_{2} \mathrm{PO}_{4}$ for several hours in air at $950{ }^{\circ} \mathrm{C}$. Large single-crystal plates of $\mathrm{Pb}_{2} \mathrm{P}_{2} \mathrm{O}_{7}$ could be produced by slow cooling $\left(1\right.$ to $\left.2^{\circ} \mathrm{C} / \mathrm{h}\right)$ of the melt in the range of 950 to $700^{\circ} \mathrm{C}$, and a homogeneous glass with the same composition could be prepared by quenching the melt between cold copper plates. $X$-ray diffraction and polarized-light analysis verified the absence of crystalline material in the $\mathrm{Pb}_{2} \mathrm{P}_{2} \mathrm{O}_{7}$ glass. HPLC analysis of the $\mathrm{Pb}_{2} \mathrm{P}_{2} \mathrm{O}_{7}$ single crystals showed that only the pyrophosphate anion $\left(\mathrm{P}_{2}\right)$ was present in agreement with the known crystal structure [17].

The chromatogram obtained for a lead pyrophosphate glass is shown at the top of Fig 6 [18]. This chromatogram shows that the glassy phase consists of a large peak corresponding to chains that are two $\mathrm{PO}_{4}$ tetrahedra in length ( $\mathrm{P}_{2}$ chains) as well as both longer and shorter phosphate chains. The average chain length computed from this chromatogram is $2 \pm 0.02$ indicating formal charge balance in the glass between the phosphate anions and the lead cations. Scanning-calorimetry measurements showed that the glass transition occurred at about $390^{\circ} \mathrm{C}$ with rapid recystallization beginning near $440^{\circ} \mathrm{C}$.

FIG. 6. HPLC chromatograms for (top) lead pyrophosphate glass as prepared; (middle) material at an intermediate state of the devitrification transition at $370{ }^{\circ} \mathrm{C}$, and (bottom) almost fully recrystallized $\mathrm{Pb}_{2} \mathrm{P}_{2} \mathrm{O}_{7}$ after $8 \mathrm{~h}$ at $370{ }^{\circ} \mathrm{C}$.

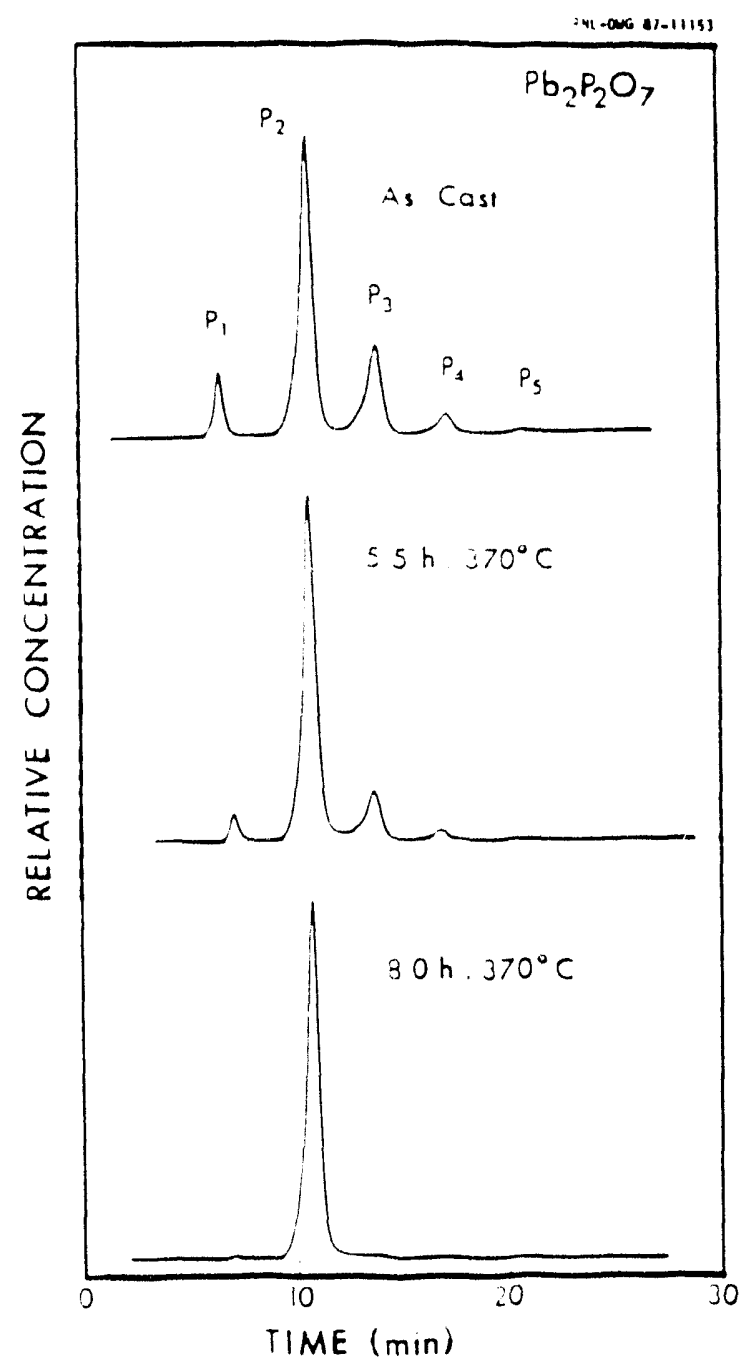


Lead pyrophosphate glass samples were isothermally annealed at temperatures above, at, and below the glass-transition temperature. The samples were then analyzed using HPLC. The middle and lower chromatograms in Fig. 6 show the results obtained for a partially devitrified and a completely recrystallized lead pyrophosphate sample, respectively. By annealing the "as-cast" glass specimens for various time periods, the detailed structural evolution of material can be mapped as it tranforms to the fully crystalline state and finally exhibits a chromatogram that consists oniy of a $\mathrm{P}_{2}$ peak.

The details of the structural evolution during the amorphous-to-crystalline transformation for annealing temperatures of 370,390 and $410^{\circ} \mathrm{C}$ are illustrated in Fig. 7. The results illustrated in Fig. 7 show that the recrystallization process consists of an induction period during which the relative change in the percentage of the various phosphate chains is small. Following this induction period, there is a relatively rapid change in the ratios of the various phosphate anions until the $\mathrm{P}_{2}$ anion associated with the crystalline state becomes predominant.
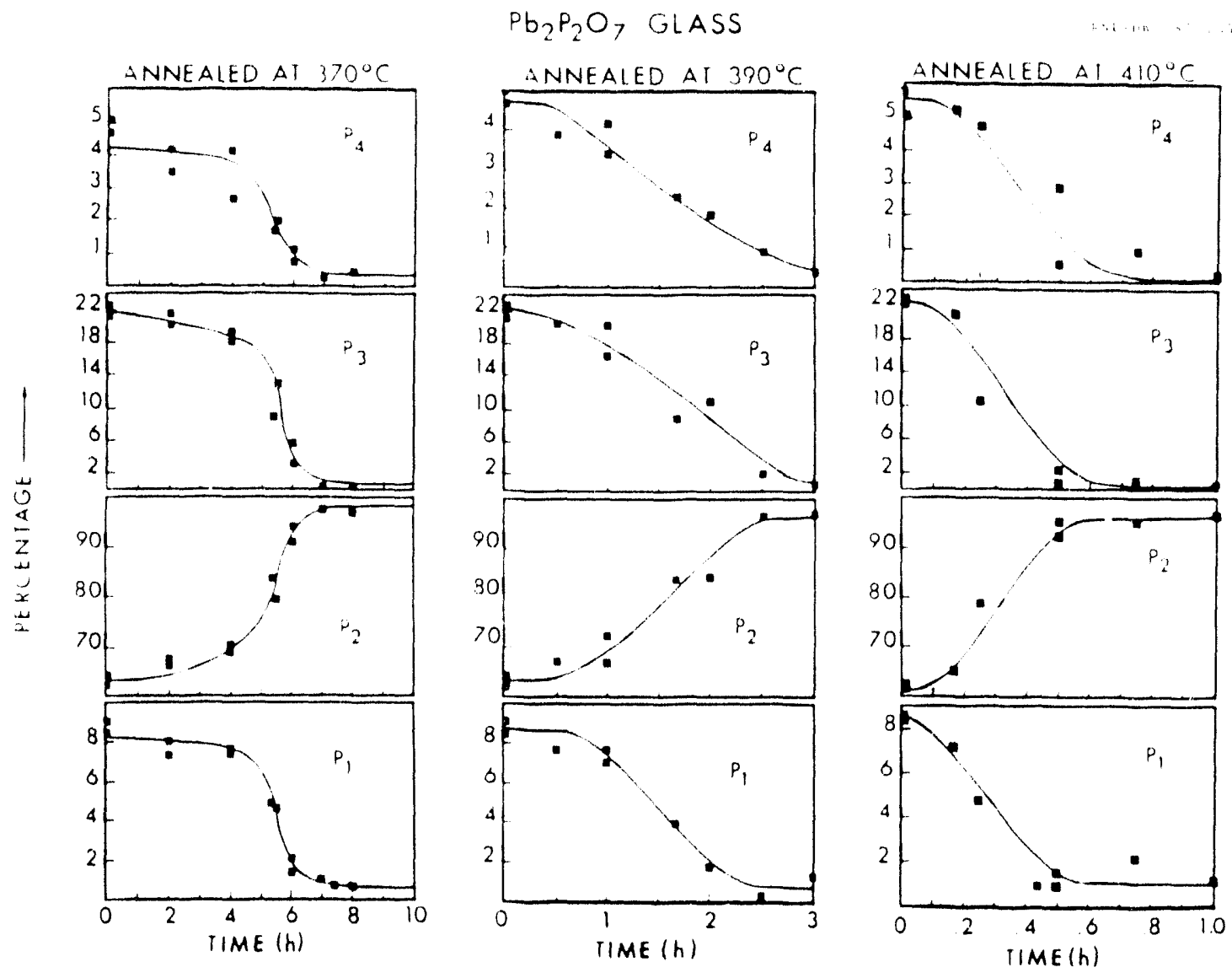

FIG. 7. The evolution with time of the relative concentration of the four major phosphate anions during the devitrification of $\mathrm{Pb}_{2} \mathrm{P}_{2} \mathrm{O}_{7}$ at 370,390 , and $410{ }^{\circ} \mathrm{C}$. The vertical axis corresponds to the percentage of the total phosphorus contained in chains of that length. 
In a traditional devitrification experiment, only the volume fraction of crystallized material is monitored as a function of time and annealing temperature. Using the HPLC technique, however, more information about the devitrification process is available since the evolution of individual phosphate anions can be followed as well during the process. For example, devitrification data are often described by a modified Avrami equation [19] of the form $x(t)=1-\exp \left[-K\left(t-t_{0}\right)^{n}\right]$ where $x$ is the volume fraction recrystallized at time $t, K$ is a thermally activated rate constant for recrystallization, $t_{0}$ is the induction period for nucleation, and $n$ is the Avrami coefficient that is used to determine the dimensionality of the controlling mechanism of recrystallization. For the data shown in Fig. 6, to corresponds to about $3 \mathrm{~h}$, and the value for $\mathrm{n}$ is close to 3 which corresponds to volume recrystallization either on preexisting nucleation sites or to interface-controlled growth. This type of analysis, however, does not utilize much of the detailed information that can be obtained with HPLC.

\section{Amorphous $\mathrm{Pb}_{2} \mathrm{P}_{2} \mathrm{O}_{7}$ Produced $\mathrm{By}$ Ion Damage}

Single crystals of $\mathrm{Pb}_{2} \mathrm{P}_{2} \mathrm{O}_{7}$ (typically $2 \times 2 \times 0.2 \mathrm{~cm}^{3}$ ) were grown from the melt as described in the previous section. In the crystal, the pyrophosphate groups ( $\mathrm{P}_{2}$ anions) are arranged in the form of sheets that are "stacked" to form a micaeous and easily cleaved crystal. One of the large surfaces of a freshly cleaved crystal (c axis) was implanted with various ions including $\mathrm{Pb}, \mathrm{O}$, or Ar. All of the remaining surfaces of the crystal were coated with silver paint so that these surfaces would be shielded when the implanted crystals were subsequently placed in the chromatography solutions. The implantation was performed at liquid nitrogen temperatures, and the energies of the implanted ions were adjusted so that the spatial extent of the resulting damage profiles were approximately the same $\left(540 \mathrm{keV} \mathrm{Pb}^{3+}, 55 \mathrm{keV} \mathrm{O}^{2+}\right.$, or $120 \mathrm{keV}$ $\mathrm{Ar}^{2+}$. An ion-damaged crystal was placed in the chromatography solution and left until the outer $100 \mathrm{~nm}$ of the implanted-crystal face was dissolved. The solution was then injected into the HPLC system and the distribution of phosphate anions was measured.

A comparison of the chromatograms obtained for lead pyrophosphate glass prepared (as described in the previous section) by thermal quenching and the chromatograms from $100 \mathrm{~nm}$ thick amorphous layers produced by ion implantation of either $\mathrm{Pb}^{3+}\left(10^{15}\right.$ ions $\left./ \mathrm{cm}^{2}\right)$ or $\mathrm{O}^{2+}\left(10^{17}\right.$ ions $\left./ \mathrm{cm}^{2}\right)$ is shown in Fig. 8 [20]. Significant structural differences are apparent between the phosphate glass and the two amorphous layers produced via ion implantation. Relative to the glass, the percentage of $\mathrm{P}_{2}$ chains is much lower for the ion-damaged layers which indicates that these layers are "more amorphous" or exhibit a higher degree of disorder than the thermally quenched glass of the same composition. In addition, the glass has a much larger percentage of $\mathrm{P}_{3}$ anions whereas the amorphous layers have significantly higher concentrations of $\mathrm{P}_{1}, \mathrm{P}_{4}, \mathrm{P}_{6}, \mathrm{P}_{7}$, and $\mathrm{P}_{8}$ anions. Figure 8 clearly illustrates that the structure of lead pyrophosphate glass is not the same as the amorphous solid of the same composition produced by ion implantation.

The HPLC resuits for a $100 \mathrm{~nm}$ layer of the implanted lead pyrophosphate crystal surface is shown in Fig. 9 for various $\mathrm{O}^{2+}$ implant doses. The HPLC results from 100 $\mathrm{nm}$ lavers of crystals implanted with either $\mathrm{Pb}^{3+}$ or $\mathrm{Ar}^{2+}$ ions are qualitatively similar 
FIG. 9. Comparison of the HPLC chromatograms from amorphous lead pyrophosphates produced by quenching the melt to for a conventional glass (top), by ion bombardment of the crystal surface with $10^{15} \mathrm{~Pb}^{3}+$ ions $/ \mathrm{cm}^{2}$ at $540 \mathrm{keV} /$ ion (middle), and by ion bombardment of the crystal with $10^{17} \mathrm{O}^{2+}$ ions $/ \mathrm{cm}^{2}$ at 55 $\mathrm{keV} /$ ion (bottom).

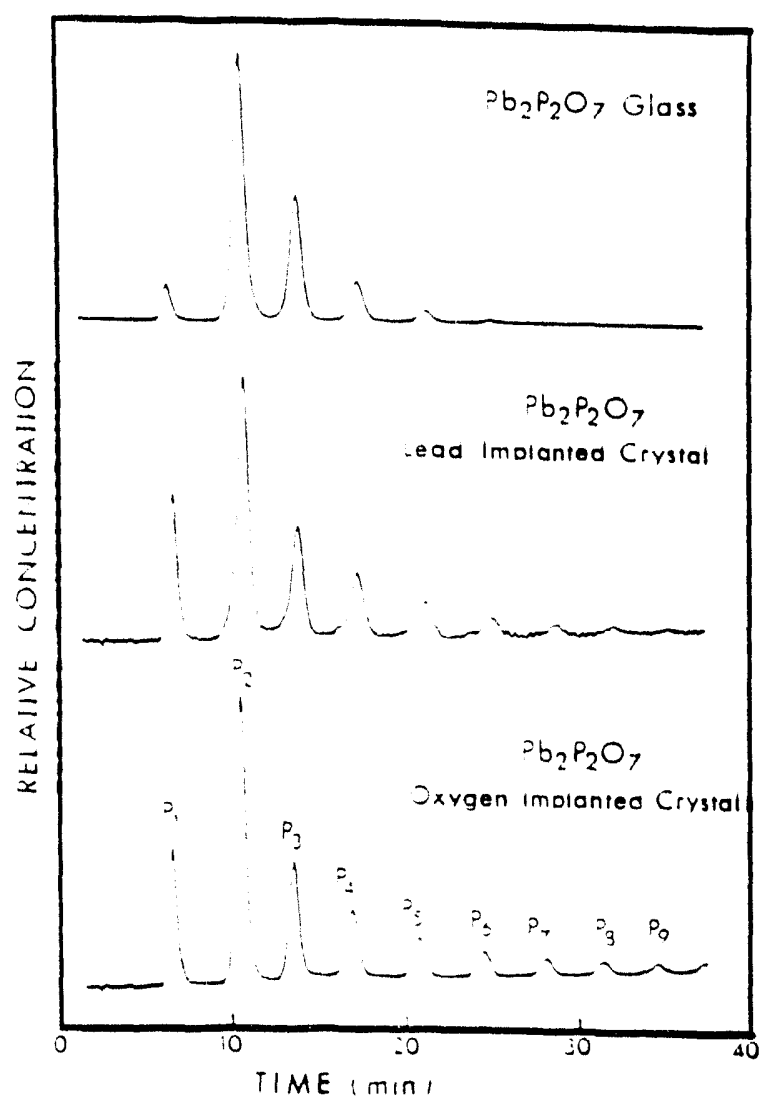

to the $\mathrm{O}^{2+}$ results and are not shown $[20,21]$. For the oxygen implanted surfaces, the first detectable alteration of the phosphate-chain structure occurs at a dose slightly less than $10^{13} \mathrm{O}^{2+}$ ions $/ \mathrm{cm}^{2}$. At doses near $10^{16} \mathrm{O}^{2+}$ ions $/ \mathrm{cm}^{2}$, the distribution of phosphate chains begins to saturate, as illustrated in Fig. 10. Note that the lead pyrophosphate glass structure is not produced for any oxygen-implant dose. For lead pyrophosphate the amorphous state produced by ion implantation is fundamentally different from the glass state produced by thermally quenching the liquid.

\section{CONCLUDING REMARKS}

The technique of HPLC has been used to characterize the crystalline-to-amorphous transition that occurs during the dehydration of $\mathrm{MgHPO}_{4} \bullet 3 \mathrm{H}_{2} \mathrm{O}$; the amorphous-tocrystalline transition that ccurs during the devitrification of $\mathrm{Pb}_{2} \mathrm{P}_{2} \mathrm{O}_{7}$; and the structure of amorphous layers produced on $\mathrm{Pb}_{2} \mathrm{P}_{2} \mathrm{O}_{7}$ single crystals by ion bombardnient. These experiments clearly demonstrate that the structure of an amorphous solid depends on how the solid was made amorphous. It was also shown 


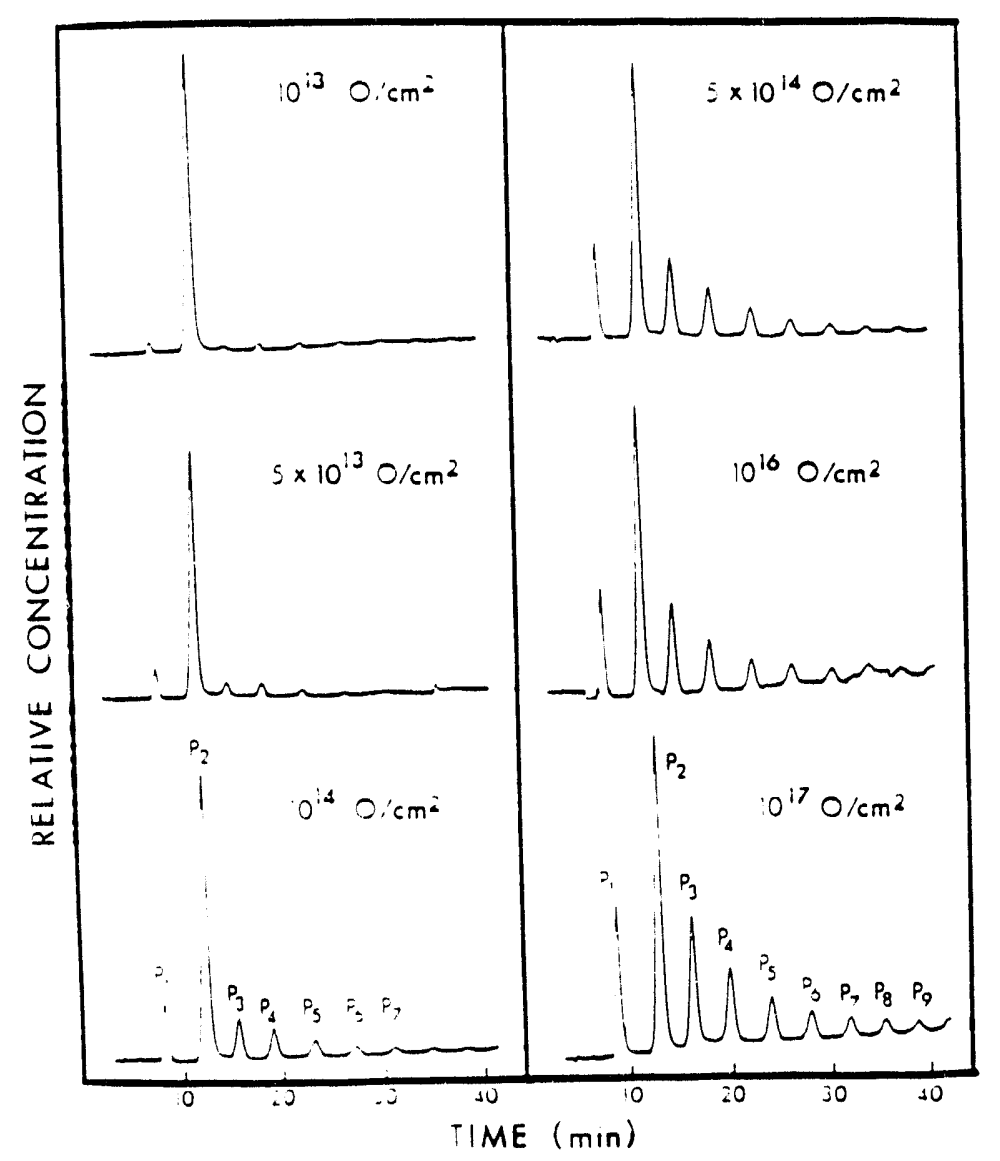

FIG. 10. HPLC results for 100nm thick layers of the surface of lead pyrophosphate single crystals that were implanted with various doses of oxygen ranging from $10^{13}$ to $10^{17} \mathrm{ions} / \mathrm{cm}^{2}$ with an energy of $55 \mathrm{keV} / \mathrm{O}$ ion.
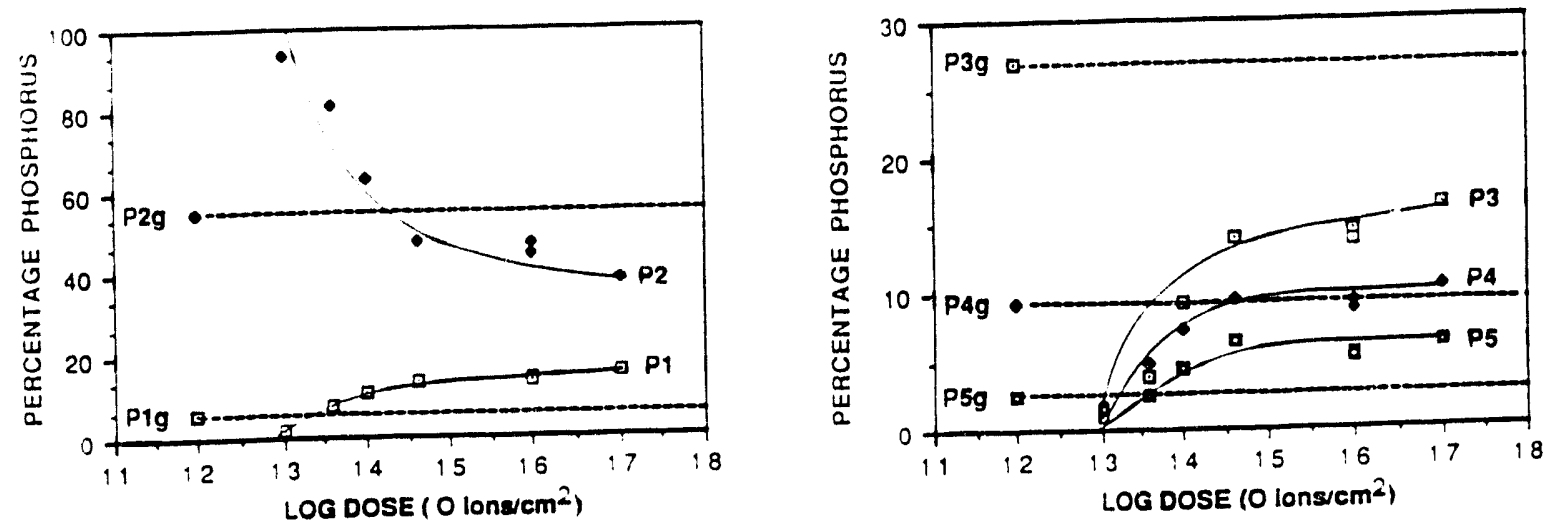

FIG. 11. The evolution with implant dose of the relative concentration of the five major phosphate anions in the ion-damaged layer. The corresponding concentrations of these same phosphate anions observed in a thermally quenched lead pyrophosphate glass are indicated by the dashed lines. The pyrophosphate glass structure is not produced at any oxygen implant dose. 
that for some solids the HPLC technique can easily distinguish differences in the amorphous state that are not apparent from diffraction data. One general goal of the present research is to use HPLC in conjunction with more traditional techniques to generate an experimental data base for a particular amorphous solid that can then be used in a realistic test of sophisticated molecular-dynamics calculations.

\section{REFERENCES}

1. J. R. Van Wazer, Phosphorus and Its Compounds:Chemistry,Vol 1, (Interscience,New York, 1958).

2. T. Kanazawa, ed.,Inorganic Phosphate Materials (Elsevier, New York, 1958).

3. G. Arrhenius, B. Gedulin, and S. Mojzsis, in Chemical Evolution and the Origin of Life, edited by C. Ponamperuma and J. Chela-Flores, Trieste, Italy, Oct 1992 , in press (A. Deepak Publishing, Hampton VA, 1993 ).

4. E. Thilo, Angew. Chem. Int. Ed. 4, 1061 (1965).

5. B. C. Bunker, G. W. Arnold, and J. A. Wilder, J. Non-Cryst. Solids 64, 291 (1984).

6. A. E. R. Westman and P. A. Gartaganis, J. Am. Ceram. Soc. 40, 293 (1957).

7. T. R. Meadowcroft and F. D. Richardson, Trans. Faraday Soc. 61, 54 (1965).

8. R. S. Ramsey, Adv. Chromatogr. 25, 219 (1986).

9. R. S. Brazell, R. W. Holmberg, and J. H. Moneyhun, J. Chromatogr. 290, 163 (1984).

10. B. C. Sales, R. S. Ramsey, J. B. Bates, and L. A. Boatner, J. Non-Cryst. Solids 87, 137 (1986).

11. T. Kanazawa, Kagaku No Ryoiki 24, 222 (1970) (in Japanese).

12. B. C. Sales, B. C. Chakoumakos, L. A. Boatner, and J. O. Ramey, J. Non-Cryst. Solids 159, 121 (1993).

13. B. C. Sales, B. C. Chakoumakos, L. A. Boatner and J. O. Ramey, J. Mater. Res. 7, 2646 (1992).

14. F. Abbona, R. Boistelle, and R. Haser, Acta Crystallogr. B35, 2514 (1978).

15. H. Barth, M. Catti, W. Joswig, and G. Ferraris, Tscher. Mineral. Petrog. Mitt. 32, 187 (1983).

16. A. Chatelain and R. A. Weeks, J. Chem. Phys. 52, 3758 (1970).

17. D. F. Mullica, H. O. Perkins, D. A. Grossie, L. A. Boatner, and B. C. Sales, J. Solid State Chem. 62, 271 (1986).

18. B. C. Sales, J. O. Ramey, and L. A. Boatner, Phys. Rev. Letters 59, 1718 (1987).

19. M. Avrami, J. Chem. Phys. 7, 1103 (1939).

20. B. C. Sales, J. O. Ramey, L. A. Boatner, and J. C. McCallum, Phys. Rev. Letters 62, 1138 (1989).

21. B. C. Sales, J. O. Ramey, J. C. McCallum, and L. A. Boatner, J. Non-Cryst. Solids 126, 179 (1990). 

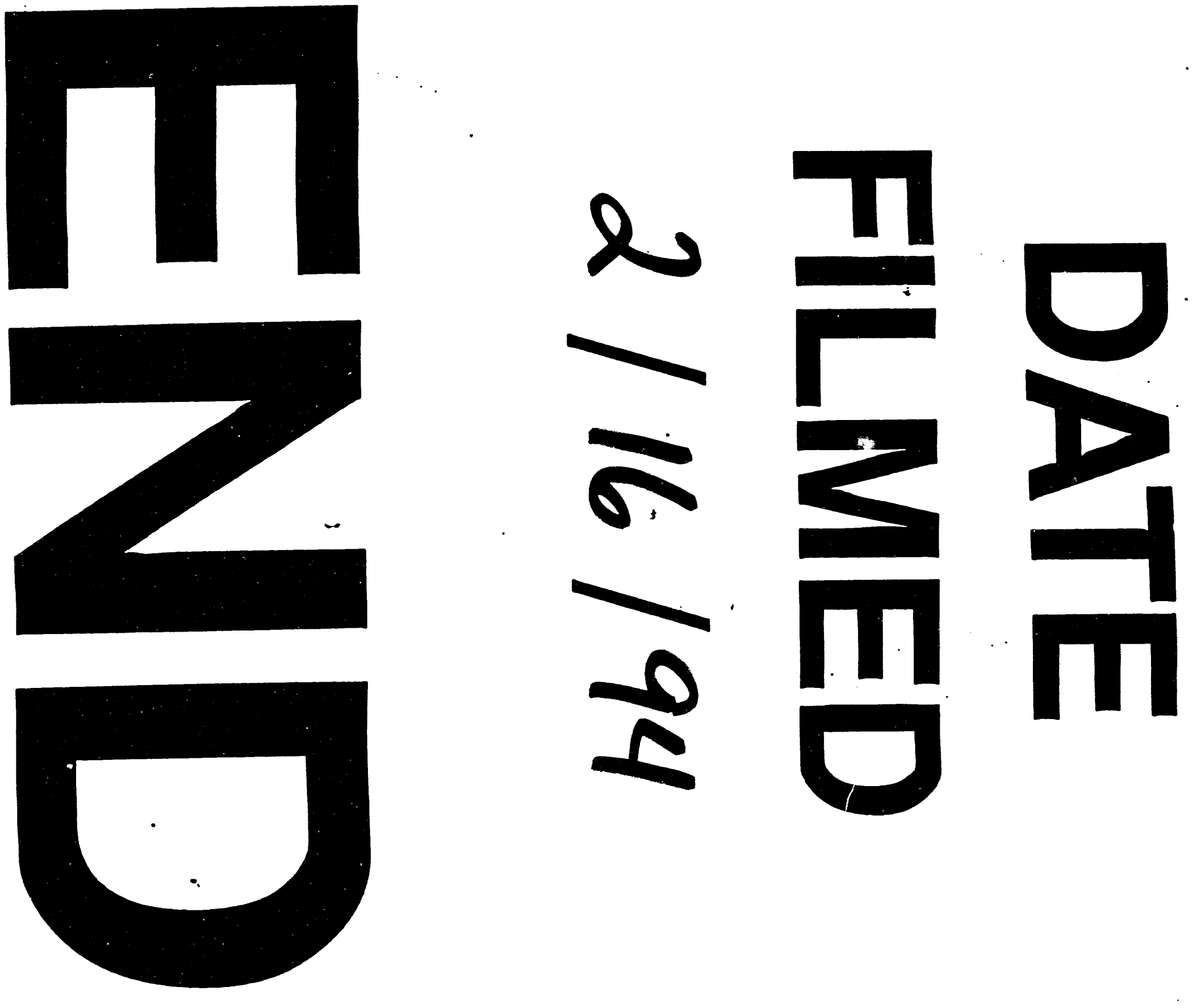
